\title{
Tetrathiafulvalene-Polychlorotriphenylmethyl Dyads: Influence of Bridge and Open-Shell Characteristics on Linear and Nonlinear Optical Properties
}

\author{
Manuel Souto, ${ }^{[a], \dagger}$ Joaquín Calbo, ${ }^{[b], \dagger}$ Imma Ratera, ${ }^{*[a]}$ Enrique Ortí, ${ }^{*[b]}$ and Jaume Veciana ${ }^{\star[a]}$
}

\begin{abstract}
In this article, three conjugated donor- $\pi$-acceptor radical systems (1a-1c) based on a tetrathiafulvalene (TTF) unit, as electron-donor, connected to a polychlorotriphenylmethyl (PTM) radical, as electron-acceptor, through different vinylene units as bridge have been synthesized. The dependence of the intramolecular charge transfer on the length of the conjugated bridge has been analysed by different electrochemical and spectroscopic techniques. In addition, linear optical properties and the secondorder non-linear optical (NLO) response of these derivatives have been theoretically calculated by comparing with their non-radical analogues (2a-2c). Interestingly, an enhanced NLO response is predicted when the PTM is in its radical form as well as when the length of the bridge becomes longer. Theoretical calculations confirm the active role of the bridge in the electronic communication between the donor TTF and the acceptor PTM units.
\end{abstract}

\section{Introduction}

The design and synthesis of novel organic materials exhibiting nonlinear optical (NLO) properties is an interesting field due to their potential applications in optoelectronic technologies. ${ }^{[1-5]}$ In particular, organic molecules which contain electron-donor (D) and electron-acceptor $(A)$ units linked by a $\pi$-conjugated bridge (D- $\pi$-A molecules as push-pull systems) have been the subject of considerable effort for the development of electro-optic switching elements for telecommunications and optical information processing. ${ }^{[6-8]}$ Remarkable characteristics of such push-pull systems are their large $\beta$ hyperpolarizabilites and the possibility of tuning this property by changing the nature of the bridge and the strengths of the donor and acceptor units. Regarding the building blocks, the tetrathiafulvalene (TTF) moiety has been widely used as an efficient electron-donor unit for synthesizing TTF- $\pi$-A structures with appealing NLO properties. Indeed, after the first example reported in 1998 by $\mathrm{N}$. Martín, J. Garín and coworkers, ${ }^{[9]}$ many other TTF-based pushpull derivatives with closed-shell electronic structure exhibiting large NLO responses have been described. ${ }^{[10-18]}$ On the other hand, molecular materials with open-shell electronic structures

[a] Dr. Manuel Souto, Dr. Imma Ratera, Prof. Jaume Veciana Institut de Ciència de Materials de Barcelona (ICMABCSIC)/CIBER-BBN

Campus Universitari de la UAB, 08193, Bellaterra, Spain E-mail: vecianaj@icmab.es

[b] Dr. Joaquín Calbo, Prof. Enrique Orti Instituto de Ciencia Molecular, Universidad de Valencia 46980 Paterna, Spain

$\dagger \quad$ These authors contributed equally.

Supporting information for this article is given via a link at the end of the document. have also aroused the interest of many researchers because of their high potentiality as NLO-phores. ${ }^{[19-24]}$ Thus, a few years ago, some of us reported the second-order non-linear optical (SONLO) response of a family of polychlorotriphenylmethyl (PTM) radical derivatives showing large $\beta$ hyperpolarizability values. $^{[25-27]}$ Interestingly, PTM radical derivatives can act as efficient electron acceptors in front of many donor molecules. ${ }^{[28]}$

In view of the donor and acceptor capabilities of both TTF and radical PTM molecules, it is of high interest to combine both units in a $D-\pi-A$ molecule and theoretically evaluate its NLO response. Recently, we have reported different $D-\pi-A$ systems based on a PTM radical electron-acceptor linked to a TTF electron-donor through conjugated vinylene bridges that exhibit a reversible switching between a neutral and a zwitterionic state in solution through the application of external stimuli ${ }^{[29-32]}$ or conductivity in solid state. ${ }^{[33-35]}$ In order to study the optical properties of this kind of radical dyads and evaluate the influence of the open-shell character and the length of the bridge, we have synthesized and characterized a family of TTF- $\pi$-PTM radical derivatives (1a-1c) and their non-radical analogues (2a2c) (Scheme 1). In this article, we present a detailed study of the intramolecular charge-transfer dependence on the open-shell structure and the bridge length of this family of compounds. Moreover, in order to study the electronic, geometrical and optical (linear and non-linear) properties of such dyads, theoretical calculations have been carried out demonstrating larger $\beta$ values for the radical dyads, compared with the nonradical ones, and upon increasing the spacer conjugation length.

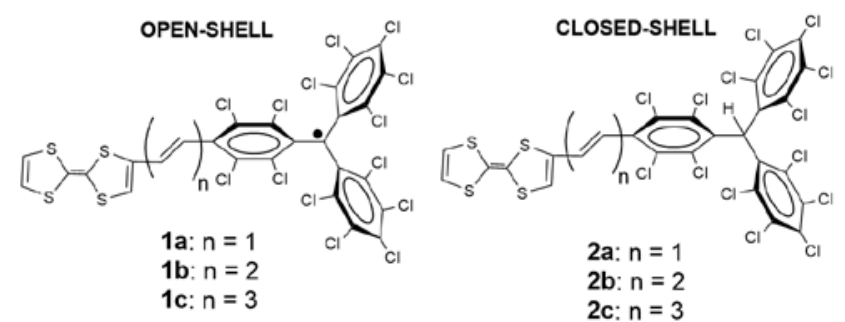

Scheme 1. Molecular structures of $D-\pi-A$ radical dyads (1a, $\mathbf{1 b}$ and $\mathbf{1 c})$ and their non-radical derivatives $(\mathbf{2} \mathbf{a}, \mathbf{2} \mathbf{b}$ and $\mathbf{2 c}$ ).

\section{Results and Discussion}

\section{Synthesis}

The synthesis of the formyl-TTF precursor $3 \mathbf{a}$ was carried out by reaction of monolithio-TTF with dimethylformamide with a yield of $69 \%$ (Scheme 2). ${ }^{[3,37]}$ The improved synthesis of $\mathbf{3 b}$ was reported by González et al. ${ }^{[11]}$ and involves the reaction of the monolithio-TTF with $\mathrm{N}, \mathrm{N}$-dimethylacrolein to yield the transvinylogue amide according to the coupling constants in the ${ }^{1} \mathrm{H}$ - 
NMR spectra. Finally, the larger formyl-TTF vinylogue $\mathbf{3 c}$ was obtained by a Wittig reaction of $\mathbf{3 b}$ with the phosphorane $\mathbf{4}$ in a $40 \%$ yield.<smiles>FC(F)C1=CSC=CS1</smiles>

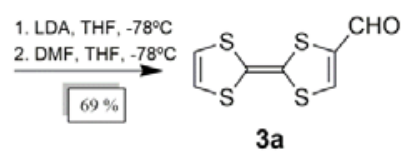<smiles>CN(/C=C/C=O)C1CC2CC21</smiles>

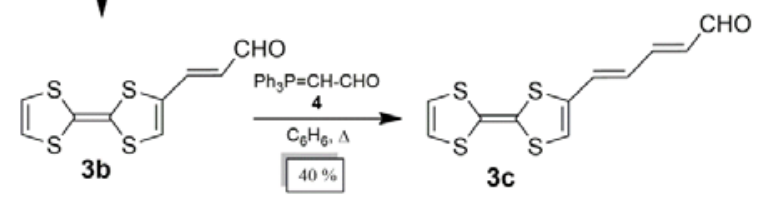

Scheme 2. Synthesis of the formyl-TTF derivatives 3a-3c.

The synthesis of all non-radical TTF- $\pi$-PTM derivatives 2a2c was carried out by a Horner-Wadsworth-Emmons reaction of the phosphonated-functionalized non-radical PTM derivative $5^{[38]}$ with the formyl-TTF derivatives $\mathbf{3 a - 3} \mathbf{c}$ (Scheme 3 ). Compounds $\mathbf{2 a}$ and $\mathbf{2} \mathbf{b}$ were obtained in $70 \%$ yield whereas $\mathbf{2} \mathbf{c}$ was obtained in moderate yield $(40 \%)$. All-trans vinylogues were obtained according to the coupling constants in the ${ }^{1} \mathrm{H}$-NMR spectra (see the Supporting Information).
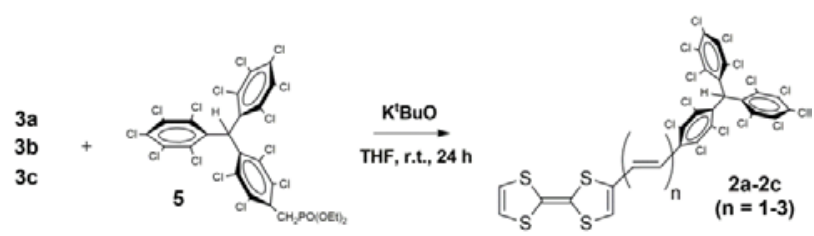

Scheme 3. Synthesis of the non-radical dyads $\mathbf{2 a - 2 c}$.

Finally, the synthesis of radicals $\mathbf{1 a - 1 c}$ involves the subsequent deprotonation of the non-radical TTF- $\pi$-PTM derivatives $\mathbf{2 a - 2 c}$ with tetrabutylammonium hydroxide (TBAOH) followed by oxidation of the formed carbanion with silver nitrate $\left(\mathrm{AgNO}_{3}\right)$, affording the final radical dyads $\mathbf{1 a - 1 c}$ with yields between 73 and $78 \%$ (Scheme 4). The radical compounds were obtained as black solids which are stable under atmospheric conditions.

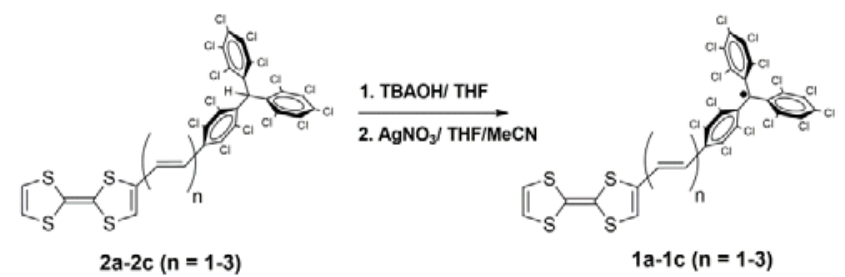

Scheme 4. Synthesis of the radical dyads 1a-1c.

\section{Electrochemical properties}

Cyclic voltammetry (CV) of radicals $\mathbf{1 a - 1 c}$, as well as their nonradical precursors 2a-2c, was performed in $\mathrm{CH}_{2} \mathrm{Cl}_{2}$ at room temperature (Figure 1 and Figure S4 in the Supporting Information, and Table 1). The CV of compounds 2a-2c show two quasi-reversible redox waves due to the stepwise oxidation of the TTF moiety to $\mathrm{TTF}^{+\cdot}$ and $\mathrm{TTF}^{2+}$ with similar redox potentials (vs. $\mathrm{Ag} / \mathrm{AgCl}$ ) of around 0.45 and $0.96 \mathrm{~V}$, respectively. As expected, the $\mathrm{CV}$ of radicals $\mathbf{1 a - 1 c}$ exhibits three waves related to the following redox pairs: $\mathrm{PTM}^{-} / \mathrm{PTM}^{*}$, $\mathrm{TTF}^{\mathrm{T}} / \mathrm{TTF}^{+\bullet}$, and $\mathrm{TTF}^{+\bullet} / \mathrm{TTF}^{2+}$. The value of $\Delta E_{\mathrm{p}}\left(=E_{\mathrm{pa}}-E_{\mathrm{pc}}\right)$ was in the range of 80-100 $\mathrm{mV}$. The oxidation potentials of the TTF moiety remain mostly unaltered for closed-shell compounds $\mathbf{2 a - 2 c}$ and equal to those of TTF. In contrast, for open-shell compounds 1a-1c, the oxidations of TTF are shifted towards more anodic values as the length of the spacer shortens, indicating a stronger interaction between the donor and acceptor groups when they become closer. The more positive values measured for $1 \mathbf{a}(0.50$ and 1.01 V) compared with $2 \mathrm{a}(0.45$ and $0.95 \mathrm{~V})$ suggest that the radical dyad exhibits a stronger interaction between the donor and the acceptor due to the enhanced electron-acceptor character of the PTM radical moiety. On the other hand, the reduction peak assigned to the $\mathrm{PTM}^{-} / \mathrm{PTM}^{*}$ process shifts toward more negative values when the bridge becomes longer, which contradicts the larger charge transfer expected for the shorter systems. This apparent discrepancy is explained below with the help of theoretical calculations on the basis of the active role played by the $\pi$-conjugated bridge in the charge-transfer process between the donor and the acceptor.

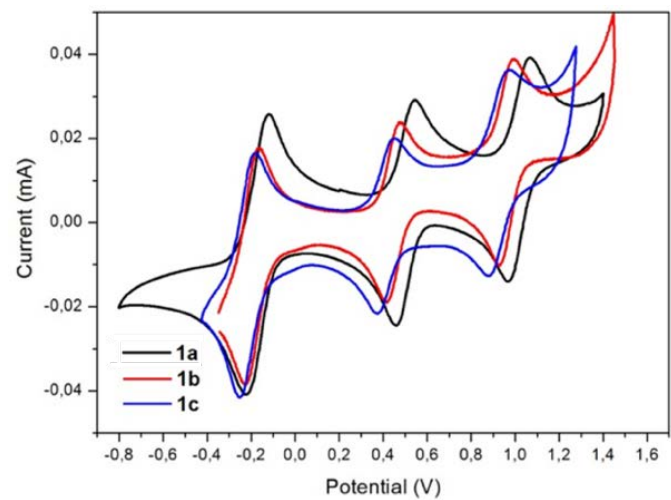

Figure 1. Cyclic voltammetry of radical compounds 1a-1c in $\mathrm{CH}_{2} \mathrm{Cl}_{2}$ vs $\mathrm{Ag} / \mathrm{AgCl}$ under Argon $\left(n-\mathrm{Bu}_{4} \mathrm{PF}_{6}(0.1 \mathrm{M})\right.$ as electrolyte, $300 \mathrm{~K}$, scan rate of 0.1 $\mathrm{V} / \mathrm{s})$.

Table 1. Electrochemical data of dyads $1 \mathrm{a}-\mathbf{1 c}$ and $2 \mathrm{a}-2 \mathrm{c}$

\begin{tabular}{|c|c|c|c|c|c|}
\hline Dyad & $\begin{array}{c}E_{1 / 2}^{\mathrm{red}]} \\
\left(1 \mathrm{e}^{-}\right)\end{array}$ & $\begin{array}{c}E_{1 / 2}^{\mathrm{ox}]} \\
\left(1 \mathrm{e}^{-}\right)\end{array}$ & $\begin{array}{c}E_{1 / 2}^{0 \times 2}{ }^{[\mathrm{a}]} \\
\left(1 \mathrm{e}^{-}\right)\end{array}$ & $\Delta E_{e / 1}(\mathrm{~V})^{[\mathrm{b}]}$ & $\Delta E_{e l 2}(\mathrm{~V})^{[\mathrm{c}]}$ \\
\hline $1 a$ & -0.16 & 0.50 & 1.01 & 0.66 & 0.51 \\
\hline $1 b$ & -0.20 & 0.44 & 0.96 & 0.64 & 0.52 \\
\hline $1 c$ & -0.22 & 0.40 & 0.92 & 0.62 & 0.52 \\
\hline $2 a$ & - & 0.45 & 0.95 & - & 0.50 \\
\hline $2 b$ & - & 0.45 & 0.96 & - & 0.51 \\
\hline $2 c$ & - & 0.46 & 0.97 & - & 0.51 \\
\hline
\end{tabular}


[a] In Volts vs $\mathrm{Ag} / \mathrm{AgCl} ; \mathrm{CH}_{2} \mathrm{Cl}_{2}$ as solvent, $\mathrm{TBAPF}_{6}$ as electrolyte and scan rate of $0.1 \mathrm{~V} / \mathrm{s}$. [b] $\Delta E_{\mathrm{el} 1}(\mathrm{~V})=E_{1 / 2}^{\mathrm{ox1}}-E_{1 / 2}^{\mathrm{red}}$. [c] $\Delta E_{\mathrm{el} 2}(\mathrm{~V})=E_{1 / 2}^{\mathrm{o} \times 2}-E_{1 / 2}^{\mathrm{ox}}$.

\section{Optical properties}

UV-vis spectra of non-radical dyads $\mathbf{2 a - 2} \mathbf{c}$ in $\mathrm{CH}_{2} \mathrm{Cl}_{2}$ are showed in the Supporting information (Figure S5). All spectra exhibit two principal bands in the $300-350$ and $400-500 \mathrm{~nm}$ regions that shift towards longer wavelengths as the bridge lengthens (Table 2). The optical gaps inferred from the lowest-energy band are larger than $2 \mathrm{eV}$ and slightly shift to the red when increasing the bridge length.

More interesting are the UV-Vis-NIR spectra in $\mathrm{CH}_{2} \mathrm{Cl}_{2}$ of radical dyads 1a-1c at $300 \mathrm{~K}$ (Figure 2 and Table 2), which can be deconvoluted in five principal peaks (Figures S6-S8). All spectra show a well-defined, intense band at $385 \mathrm{~nm}$ that is characteristic of chromophores incorporating the PTM radical. ${ }^{[28]}$ Two less-resolved peaks appear at lower energies for $\mathbf{1 a}(426$ and $518 \mathrm{~nm}), \mathbf{1 b}(456$ and $568 \mathrm{~nm}$ ) and 1c (475 and $607 \mathrm{~nm})$, which are attributed to the electronic conjugation of the unpaired electron into the $\pi$-conjugated framework. The tendency of these bands to shift towards lower energies when increasing the bridge length is in agreement with a higher electron delocalization over the vinylene units. Finally, the appearance of a broad band is observed in the $900-1100 \mathrm{~nm}$ range, which is assigned to an intramolecular charge-transfer (ICT) process from the TTF unit to the PTM radical. The optical gaps calculated from the lowest-energy band $(\sim 1 \mathrm{eV})$ are smaller than those obtained for the non-radical analogues, in agreement with the stronger electron-acceptor character of the PTM radical unit and the presence of the semi-occupied molecular orbital (SOMO) which appear at lower energies (see the theoretical calculations below)

Table 2. UV-vis-NIR data for compounds 1a-1c and 2a-2c in $\mathrm{CH}_{2} \mathrm{Cl}_{2}$. Experimental and theoretical optical gap $\left(\Delta E_{\mathrm{opt}}\right)$.

\begin{tabular}{cccc}
\hline Dyad & $\lambda_{\text {max }} / \mathrm{nm}\left(10^{-3} \times \varepsilon / \mathrm{M}^{-1} \mathrm{~cm}^{-1}\right)$ & $\begin{array}{c}\Delta E_{\mathrm{opt}, \mathrm{exp}} \\
(\mathrm{eV})^{\mathrm{a}}\end{array}$ & $\begin{array}{c}\Delta E_{\mathrm{opt}, \text { theor }} \\
(\mathrm{eV})^{b}\end{array}$ \\
\hline 1a & $\begin{array}{c}295(20.6) ; 323(\mathrm{sh}) ; 385(26) ; \\
426(15) ; 518(4.3) ; 957(0.6)\end{array}$ & 1.07 & 1.13 \\
\hline 1b & $\begin{array}{c}273(\mathrm{sh}) ; 326(21.8) ; 385(29.3) ; \\
456(12.3) ; 568(4.5) ; 942(0.6)\end{array}$ & 1.08 & 1.09 \\
\hline 1c & $\begin{array}{l}340(24.9) ; 385(30.1) ; 475 \\
(15.9) ; 607(7.4) ; 918(0.7)\end{array}$ & 1.09 & 1.07 \\
\hline 2a & $290(\mathrm{sh}) ; 322(28.4) ; 456(5.4)$ & 2.20 & 2.74 \\
\hline 2b & $289(\mathrm{sh}) ; 332(26.4) ; 463(5.4)$ & 2.15 & 2.55 \\
\hline 2c & $278(\mathrm{sh}) ; 355(24.8) ; 471(6.4)$ & 2.10 & 2.43 \\
\hline
\end{tabular}

${ }^{a}$ Experimental optical gaps are calculated from the onset of the lowest-energy absorption band. ${ }^{b}$ Theoretical optical gaps are calculated as the energy difference between the SOMO and HOMO in radical 1a-1c, and between the LUMO and HOMO in non-radical 2a-2c.

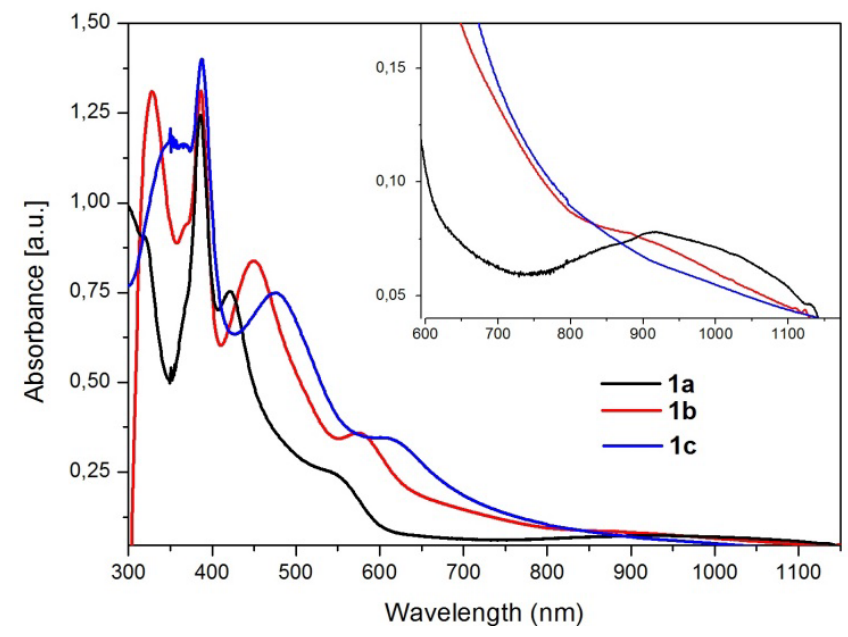

Figure 2. UV-vis-NIR spectra of a solution $0.05 \mathrm{mM}$ of dyads $1 \mathrm{a}-1 \mathrm{c}$ in $\mathrm{CH}_{2} \mathrm{Cl}_{2}$. Inset shows an amplification of the low-energy range of the spectra.

\section{Magnetic properties}

The ESR spectra of radicals $\mathbf{1 a}, \mathbf{1 b}$ and $\mathbf{1 c}$ in toluene $/ \mathrm{CH}_{2} \mathrm{Cl}_{2}$ $(0.05 \mathrm{mM}$ at $220 \mathrm{~K})$ show three partially overlapped main lines centred at different $g$-values (Figure 3 and Table 3). The shift of the $g$ factor to higher values recorded from $\mathbf{1 a}$ to $\mathbf{1 c}$ indicates larger delocalization of the $\alpha$-SOMO over the $\pi$-conjugated framework. The three overlapped lines observed at $220 \mathrm{~K}$ with slightly different hyperfine coupling constants $\left(a_{1}(H)\right.$, Table 3$)$ can be ascribed to the coupling of the unpaired electron with two ${ }^{1} \mathrm{H}$ atoms of the vinylene bridges (Figure 3 ).

Table 3. ESR parameters used for the simulation of the experimental X-band spectra of $1 \mathrm{a}-1 \mathrm{c}$ radicals.

\begin{tabular}{ccc}
\hline Dyad & $g$-value & $a_{1}(\mathrm{H})(\mathrm{G})$ \\
\hline 1a & 2.0025 & 1.10 \\
1b & 2.0026 & 1.07 \\
1c & 2.0028 & 1.04 \\
\hline
\end{tabular}

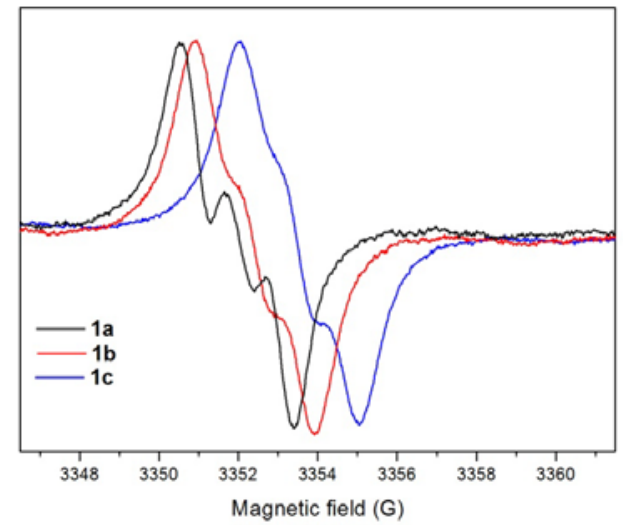


Figure 3. ESR spectra of $0.05 \mathrm{mM}$ solutions of dyads 1a-1c in toluene $/ \mathrm{CH}_{2} \mathrm{Cl}_{2}$ at $220 \mathrm{~K}$.

\section{Theoretical calculations}

Frontier molecular orbitals. Theoretical calculations were performed for the family of both radical and non-radical donor- $\pi$ acceptor TTF- $\pi$-PTM derivatives under the density functional theory (DFT) framework. Geometry optimizations were carried out at the B3LYP/6-31G** level of theory including solvent effects (see the Supporting Information for full computational details). Minimum-energy structures of 2a-2c show the TTF unit, which exhibits the typical boat shape, nearly coplanar to the conjugated vinylene bridge, whereas the benzene ring connecting the PTM unit with the bridge presents a dihedral angle of $\sim 43^{\circ}$ with respect to the plane of the bridge (Figure S11). Minimum-energy geometries of the radical analogues 1a1c show similar structural characteristics. Note that two main conformers arise from the relative orientation of the TTF unit with respect to the $\pi$-conjugated bridge: the $\mathrm{s}$-cis and $\mathrm{s}$-trans isomers (Figure S12). Theoretical calculations predict the s-trans isomer $3 \mathrm{kcal} / \mathrm{mol}$ more stable than the s-cis for both 1a-c and 2a-c. Hence, the following analysis refers only to the s-trans isomers. a)

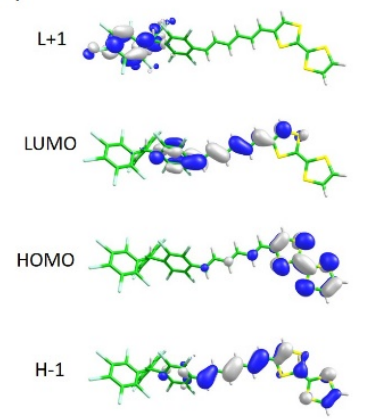

b)

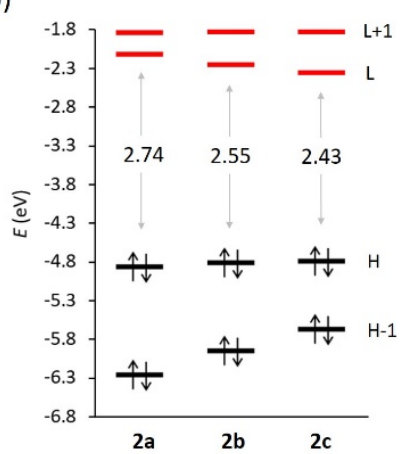

Figure 4. a) Isovalue contours ( \pm 0.03 a.u.) calculated for the frontier molecular orbitals of $2 \mathrm{c}$ at the B3LYP/6-31G** level in $\mathrm{CH}_{2} \mathrm{Cl}_{2}$. b) Energy diagram of the frontier molecular orbitals for $\mathbf{2 a - c}$

Figure 4 a displays the isovalue contours calculated for the frontier molecular orbitals of $\mathbf{2 c}$ as a representative example. Similar contours are obtained for $\mathbf{2} \mathbf{a}$ and $\mathbf{2 b}$ (Figure S13). The highest-occupied molecular orbital (HOMO) is calculated to be mostly localized on the TTF unit, whereas the second lowestunoccupied molecular orbital, the LUMO+1, is centred on the PTM fragment. Otherwise, the HOMO-1 and the LUMO spread mainly over the $\pi$-conjugated bridge and contain important contributions from the TTF and PTM fragments, respectively. Therefore, upon increasing the length of the bridge, the HOMO1 and LUMO increase and decrease in energy, respectively, whereas the HOMO and LUMO+1 energies are barely affected due to their more localized character (Figure 4b). As a consequence, the HOMO-LUMO energy gap of the non-radical species is systematically reduced upon increasing the bridge length, going from $2.74 \mathrm{eV}$ in $\mathbf{2 a}$ to $2.43 \mathrm{eV}$ in $\mathbf{2 c}$. Based on time-dependent DFT (TDDFT) calculations, the lowest-energy UV-vis band experimentally recorded in the $450-470 \mathrm{~nm}$ region (Table 2) is attributed to the HOMO $\rightarrow$ LUMO transition, which is calculated at lower energies upon increasing the bridge length (Figure S14). This transition implies a certain degree of charge transfer from the TTF unit to the bridge+PTM region (Figure 4a) The intense electronic transition observed in the $320-350 \mathrm{~nm}$ range is assigned to the $\pi-\pi^{\star}$ HOMO- $1 \rightarrow$ LUMO monoexcitation and mainly implies the vinylene bridge (Figure $4 \mathrm{a}$ ). It is predicted at lower energies going from $\mathbf{2 a}$ to $\mathbf{2 c}$ (Figure S14) in good agreement with the experimental observations.

a)

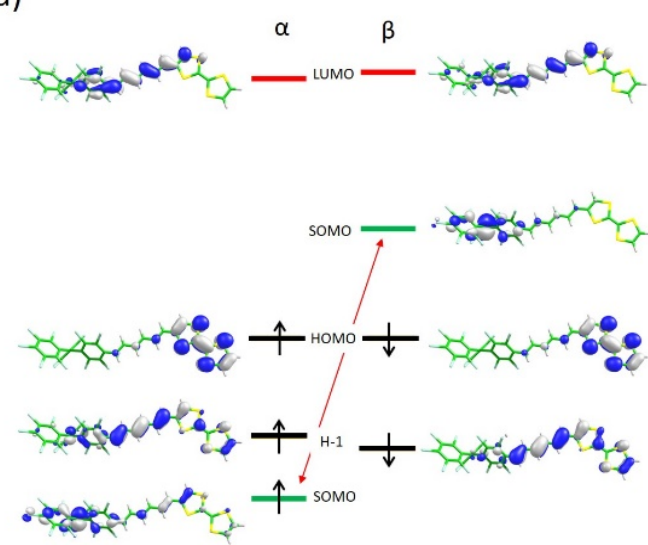

b)

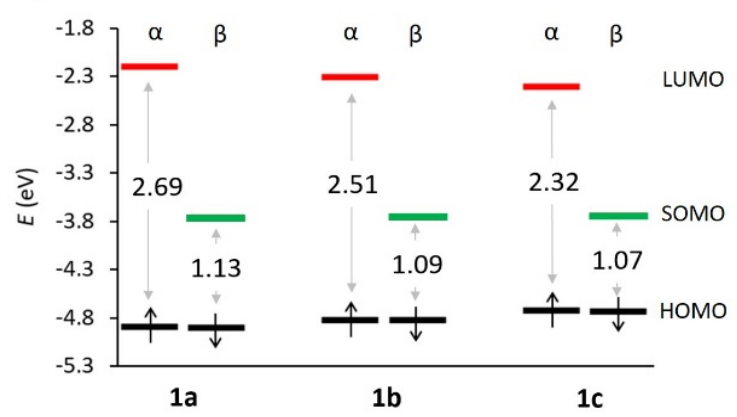

Figure 5. a) Isovalue contours ( \pm 0.03 a.u.) calculated for the frontier molecular orbitals of $1 \mathrm{c}$ at the $\mathrm{B} 3 \mathrm{LYP} / 6-31 \mathrm{G}^{\star *}$ level in $\mathrm{CH}_{2} \mathrm{Cl}_{2}$. b) Energy diagram showing the frontier molecular orbitals for 1a-c.

The topologies calculated for the frontier molecular orbitals of the radical species 1a-c are comparable to those obtained for the non-radical analogues. Figure $5 a$ shows those computed for 1c as a representative example (see Figure S15 for 1a). As for 2a-c, the $\alpha$ and $\beta$ HOMOs are located on the TTF unit. In contrast, the SOMO is essentially localized over the acceptor PTM fragment. The lowest energy gap in the radical compounds 1a-c therefore corresponds to the HOMO-SOMO $\beta$ gap, which is computed nearly constant $(\sim 1.1 \mathrm{eV})$ along the 1a-c family due to the negligible participation of the bridge in both the HOMO and the SOMO (Figure 5). The HOMO $\rightarrow$ SOMO excitation implies a charge transfer from the TTF unit to the PTM moiety and gives rise to the low-lying broad ICT absorption band experimentally recorded in the $950 \mathrm{~nm}$ region (Figure 2). The values predicted theoretically for the HOMO-SOMO gap are in 
very good accord with the optical gap deduced from the UV-visNIR spectra (Table 2).

Charge and spin-density distributions. To scrutinize the effect that the length of the bridge has on the electron transfer between the TTF and PTM fragments, the electronic distribution was analysed by performing a natural population analysis (NPA) at the B3LYP/6-31G** level. For 1a-c, theoretical calculations indicate that the TTF fragment has a large positive charge that increases upon shortening the bridge length (from $+0.24 \mathrm{e}$ in $\mathbf{1 c}$ to +0.27 e in $1 \mathrm{a}$; Figure 6 ), evidencing the enhanced electron communication between TTF and PTM for short-length bridges. Logically, the NPA charge accumulated by the bridge plus the acceptor PTM unit has the same trend but with opposite sign (Figure 6). However, by analysing the bridge and the PTM fragments separately, we predict that the acceptor PTM contains an absolute negative charge that becomes slightly larger upon increasing the bridge length (Figure 6). This amount of charge does not come from the TTF fragment, which is further from PTM along the a-c series, but from the $\pi$-conjugated bridge, which redistributes its charge with a partial electron donation to the PTM. The same trends are qualitatively reproduced for the closed-shell analogues $\mathbf{2 a - 2 c}$, but with a global reduced electron acceptor ability of PTM (Figure 6). Theoretical results therefore confirm the active role of the $\pi$-conjugated bridge, suggesting that it does not only impact on the donor-acceptor separation but directly participates in the charge-transfer process.

Figure 7 shows the spin-density distributions calculated for the neutral and charged species of $\mathbf{1 c}$ and $\mathbf{2 c}$ as representative examples. Calculations indicate that the unpaired electron in the 1a-c systems is located on the PTM unit, slightly spreading over the $\pi$-conjugated bridge (Figure 7 and S18). The spin-density distribution computed for the charged species allows for the assignment of the redox processes taking place in the cyclic voltammetry experiments. For the non-radical systems $2 \mathbf{a}-\mathbf{2 c}$, the first and second oxidations take place on the donor TTF moiety, with a significant contribution of the $\pi$-conjugated bridge, and a closed-shell dication is obtained (Figure 7). For the cation, the TTF core evolves to a planar structure as it is the case for isolated $\mathrm{TTF}^{+*}$, whereas the $\mathrm{TTF}^{2+}$ unit presents an inter-ring twisting of $36^{\circ}$ for $2 c^{2+}$. Likewise, a similar picture is predicted for the radical analogues. In $\mathbf{1 a - 1 c}$, the first oxidation takes place in the TTF moiety, and a triplet cation with one unpaired electron localized on each moiety (PTM and TTF) is generated (Figure 7) The second oxidation in the 1a-1c compounds takes place again on the TTF unit, forming a radical dication with one unpaired electron in the PTM fragment. As expected, the reduction process in 1a-c originates in the PTM unit and gives rise to a negatively charged closed-shell species.
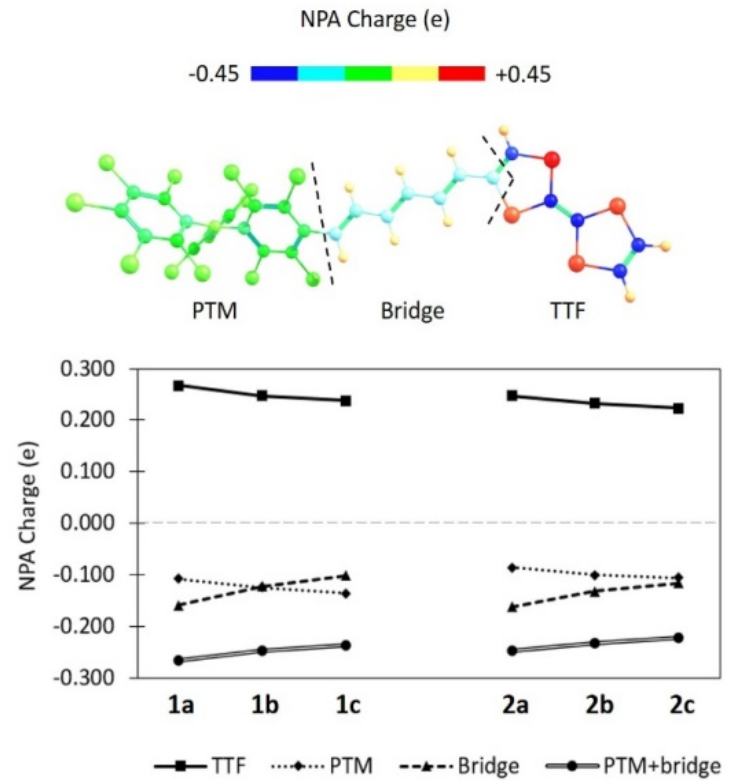

Figure 6. Accumulated NPA charges calculated for molecular fragments of 1ac and $2 a-c$ at the B3LYP/6-31G** level including solvent effects. Molecula fragments definition and atomic charges identification with colours are included in the upper part for the representative 1c dyad.

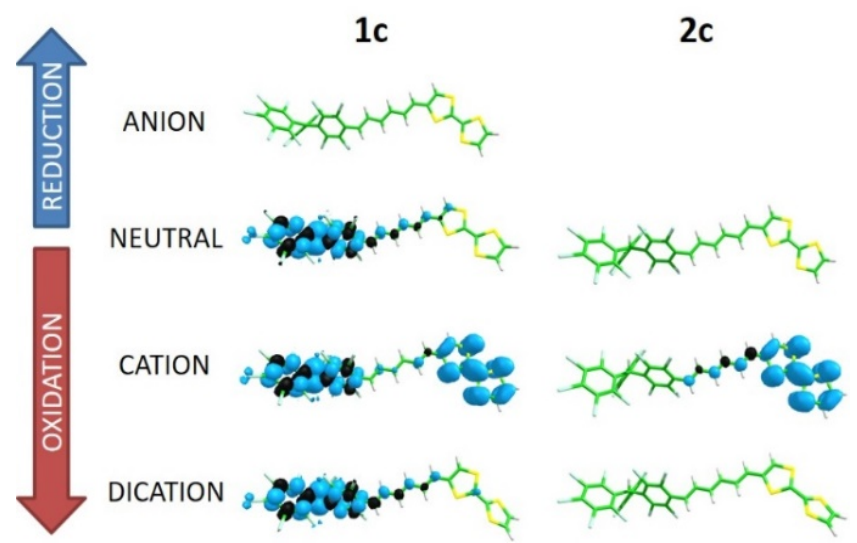

Figure 7. Spin densities calculated for neutral and charged species of representative compounds $1 \mathrm{c}$ and $2 \mathrm{c}$ at the CAM-B3LYP/6-31G** level of theory in $\mathrm{CH}_{2} \mathrm{Cl}_{2}$.

NLO properties. Theoretical first hyperpolarizabilities were finally computed for the radical $\mathbf{1 a - c}$ and non-radical 2a-c derivatives at the BH\&HLYP/6-31G** level of theory (Figure 8) to assess the NLO response in our D- $\pi$-A dyads (see the Supporting Information for full computational details). Nonradical 2a-c dyads are predicted with $\beta$ values ranging $73-225 \times$ $10^{-30}$ esu. Calculations demonstrate that radical push-pull derivatives provide larger hyperpolarizabilities compared to the non-radical analogues, with $\beta$ values in the range of 202-601 $\times$ $10^{-30}$ esu. Moreover, a systematic enhancement of the NLO response is achieved by increasing the bridge length (Figure 8). It is important to note that the $\beta$ hyperpolarizabilities calculated for our radical $D-\pi$-A dyads surpass those reported for similar closed-shell TTF-A dyads, which are in the order of 200-500 $\times$ $10^{-30} \mathrm{esu}^{[11,17,18]}$ and for the unsubstituted PTM radical $(362 \times$ $10^{-30}$ esu). ${ }^{[26]}$ 


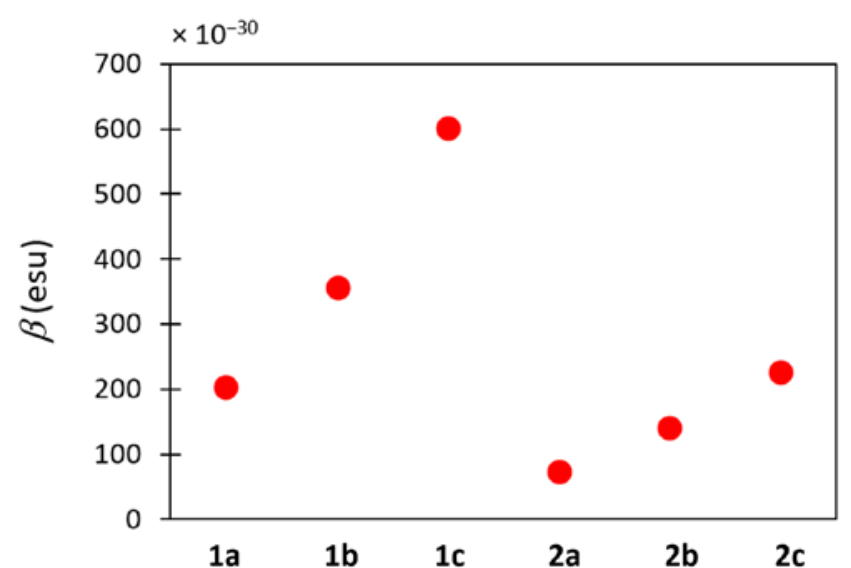

Figure 8. Theoretical $\beta$ hyperpolarizabilities calculated at the BH\&HLYP/ $6-31 G^{* *}$ level of theory in $\mathrm{CH}_{2} \mathrm{Cl}_{2}$.

\section{Conclusions}

In summary, we have reported the synthesis of a new family of TTF- $\pi$-PTM dyads that have been fully characterized by multiple spectroscopic techniques in order to analyse the intramolecular charge transfer between the electron-donor TTF and the electron-acceptor PTM radical. DFT calculations allowed understand the geometrical and electronic properties of such dyads, indicating an active role of the bridge as well as of the radical/non-radical nature of PTM in the charge-transfer process. The second-order non-linear optical (NLO) properties of the TTF- $\pi$-PTM derivatives have been theoretically calculated, demonstrating a direct dependence on the bridge length and an enhancement of the NLO response for the open-shell dyads.

\section{Experimental Section}

\section{General Methods}

${ }^{1} \mathrm{H}$ NMR spectra were recorded using Bruker Avance 250, 400, 500 instruments and Me4Si as an internal standard. Infrared spectra were recorded with a Spectrum One FT-IR Spectroscopy instrument and UV/Vis/NIR spectra were measured using a Cary 5000E Varian. ESR spectra were performed with a Bruker ESP $300 \mathrm{E}$ equipped with a rectangular cavity T102 that works with an X-band $(9.5 \mathrm{GHz})$. The solutions were degassed by argon bubbling before the measurements. LDI/TOF MS were recorded in a Bruker Ultraflex LDI-TOF spectrometer. Cyclic voltammetry measurements were obtained with a potentiostat 263a from EG\&G Princeton Applied Research in a standard 3 electrodes cell. All reagents and solvents employed for the syntheses were of high purity grade and were purchased from Sigma-Aldrich Co., Merck, and SDS. Dry solvents were used in the chemical reactions and in the cyclic voltammetries. The solvents used for optical spectroscopy and ESR measurements were of HPLC grade (ROMIL-SpS). In addition, for cyclic voltammetry experiments, $\mathrm{CH}_{2} \mathrm{Cl}_{2}$ was filtered over basic alumina to eliminate the acidic residues.

\section{Compound 3a}

$1.00 \mathrm{~g}(4.9 \mathrm{mmol})$ of tetrathiafulvalene, previously recrystallized from heptane, was dissolved in $60 \mathrm{~mL}$ of anhydrous THF under an inert atmosphere. Then, it was cooled down to $-78{ }^{\circ} \mathrm{C}$ with an acetone/ $\mathrm{N}_{2}$ bath and $3.13 \mathrm{~mL}$ of LDA $(1.8 \mathrm{M})$ were added and stirred for 90 minutes to obtain the lithiated TTF-derivative. After that, $1.20 \mathrm{~mL}(15.5 \mathrm{mmol})$ of anhydrous $N, N$-dimethylformamide (DMF) were added to the solution, which was stirred for 2 extra hours. Then, the mixture was acidified with hydrochloridric acid (2 M), extracted with $\mathrm{CH}_{2} \mathrm{Cl}_{2}$, and washed with water. The organic phase was dried with anhydrous magnesium sulfate, filtrated, and the solvent was evaporated under reduced pressure. The product was purified by column chromatography of silica gel using a mixture of hexane and $\mathrm{CH}_{2} \mathrm{Cl}_{2}$ as eluent (1:1). $0.79 \mathrm{~g}(69 \%)$ of the final product were obtained. Characterization: LDI-TOF (positive mode): $\mathrm{m} / \mathrm{z}$ (amu/e): $233.37\left(\mathrm{M}^{+\cdot}\right){ }^{1} \mathrm{H}-\mathrm{RMN}(250 \mathrm{MHz}, \mathrm{CDCl} 3, \delta(\mathrm{ppm})): 9.48(\mathrm{~s}, 1 \mathrm{H}, \mathrm{CHO}) ; 7.43$ (s, 1H, CH); 6.33 (s, 2H, CH). FT-IR $\left(v\left(\mathrm{~cm}^{-1}\right)\right): 3267(\mathrm{w}) ; 3063(\mathrm{w}) ; 3038$ (w); 2920 (w); 2281 (w); 2114 (w); 1786 (w); 1713 (w); 1662 (s); 1645 (s); $1561(\mathrm{~m}) ; 1550(\mathrm{~m}) ; 1532(\mathrm{~s}) ; 1515(\mathrm{~s}) ; 1472(\mathrm{~m}) ; 1368(\mathrm{~m}) ; 1287(\mathrm{~m})$; $1252(\mathrm{~m}) ; 1228(\mathrm{~m}) ; 1143(\mathrm{~s}) ; 1075(\mathrm{~m}) ; 1000(\mathrm{~m}) ; 983(\mathrm{~m}) ; 866(\mathrm{w}) ; 829$ $(\mathrm{m}) ; 788(\mathrm{~s}) ; 775(\mathrm{~s}) ; 737(\mathrm{~m}) ; 697(\mathrm{~m})$.

\section{Compound 3b}

$550 \mathrm{mg}(2.70 \mathrm{mmol})$ of tetrathiafulvalene were dissolved in $40 \mathrm{~mL}$ of anhydrous THF under $\mathrm{Ar}$ atmosphere. Then it was cooled to $-78{ }^{\circ} \mathrm{C}$ and $1.70 \mathrm{~mL}$ of a $2 \mathrm{M}$ solution of lithium diisopropylamide (LDA) in tetrahydrofuran were added to the solution and stirred for 60 minutes. Then, $0.5 \mathrm{~mL}$ (5.2 mmol) of 3-(dimethylamino)-acrolein were added and the solution was stirred for two hours. Afterwards, the mixture was acidified with hydrochloric acid $(2 \mathrm{M})$, extracted with $\mathrm{CH}_{2} \mathrm{Cl}_{2}$ and washed with water. The organic phase was dried with anhydrous magnesium sulfate, filtrated and the solvent was evaporated under reduced pressure. The product was purified by column chromatography of silica gel using a mixture of hexane and ether to yield $430 \mathrm{mg}(62 \%)$ of TTF-CH=CH-CHO (3b) as a dark red-brownish solid. Characterization: ${ }^{1} \mathrm{H}-\mathrm{NMR}(250 \mathrm{MHz}$, $\left.\mathrm{CDCl}_{3}, \delta(\mathrm{ppm})\right): 9.58(\mathrm{~d}, 1 \mathrm{H}, \mathrm{J}=7.4 \mathrm{~Hz}, \mathrm{CHO}) ; 7,17(\mathrm{~d}, 1 \mathrm{H}, \mathrm{J}=15.4 \mathrm{~Hz}$ $\mathrm{CH}-\mathrm{CHO}) ; 6.87(\mathrm{~s}, 1 \mathrm{H}) ; 6.35(\mathrm{~s}, 2 \mathrm{H}) ; 5.96(\mathrm{dd}, 1 \mathrm{H}, \mathrm{J}=15.4,7.4 \mathrm{~Hz}$, $\mathrm{CH}=\mathrm{CH}-\mathrm{CHO})$. FT-IR $\left(v\left(\mathrm{~cm}^{-1}\right)\right): 3063(\mathrm{w}) ; 2955(\mathrm{w}) ; 2921(\mathrm{~m}) ; 2851(\mathrm{~m})$; 1738 (w); 1660 (s, C=O); 1600 (s, CH=CH); $1522(\mathrm{~m}) ; 1511(\mathrm{~m}) ; 1458$ (w); 1382 (w); 1252 (w); 1216 (w); 1157 (w); 1112 (s); 1001 (w); 953 (s); $830(\mathrm{~m}) ; 795(\mathrm{~m}) 754(\mathrm{~s}) ; 728(\mathrm{~m}) ; 669(\mathrm{~m})$. LDI-TOF (positive mode): $\mathrm{m} / \mathrm{z}\left(\mathrm{amu} / \mathrm{e}^{-}\right): 257.722\left(\mathrm{M}^{++}\right)$.

\section{Compound 3c}

A solution of triphenylphosphoranylidene-acetaldehyde (212 $\mathrm{mg}, 0.7$ $\mathrm{mmol})$ and $3 \mathrm{~b}(90 \mathrm{mg}, 0.35 \mathrm{mmol})$ in benzene $(20 \mathrm{~mL})$ was refluxed under Ar for 3 hours. After cooling, hexane $(30 \mathrm{~mL})$ was added and the precipitated $\mathrm{Ph}_{3} \mathrm{PO}$ was filtered. The solvent was evaporated and the product was purified by column chromatography using hexane/ $\mathrm{Et}_{2} \mathrm{O}$ (90:10) to obtain $40 \mathrm{mg}(40 \%)$ of TTF- $\mathrm{CH}=\mathrm{CH}-\mathrm{CH}=\mathrm{CH}-\mathrm{CHO}$ (3c) as a red solid. Characterization: ${ }^{1} \mathrm{H}-\mathrm{NMR}\left(250 \mathrm{MHz}, \mathrm{CDCl}_{3}, \delta(\mathrm{ppm})\right): 9.57$ (d, $1 \mathrm{H}, \mathrm{J}=7.9 \mathrm{~Hz}, \mathrm{CHO}) ; 7,10$ (dd, $1 \mathrm{H}, \mathrm{J}=15.2,11.0 \mathrm{~Hz}) ; 6.73(\mathrm{~d}, 1 \mathrm{H}, \mathrm{J}=$ $15.1 \mathrm{~Hz}) ; 6.59$ (s, 1H); 6.33 (s, 2H); 6,26 (dd, $1 \mathrm{H}, \mathrm{J}=14.5,11.2 \mathrm{~Hz}) ; 6,20$ (dd, $1 \mathrm{H}, J=14.5,7.6 \mathrm{~Hz})$. FT-IR $\left(v\left(\mathrm{~cm}^{-1}\right)\right)$ : $3063(\mathrm{w}) ; 2981(\mathrm{w}) ; 2848(\mathrm{w})$; 1660 (s, C=O); 1602 (s, CH=CH); 1582 (s, CH=CH); 1504 (s); 1392 (w); 1289 (w); 1246 (w); 1140 (s); 1108 (s); 1006 (m); 975 (s); 830 (w); 795 $(\mathrm{m}) ; 776(\mathrm{~m}) ; 750(\mathrm{~m})$. LDI-TOF (positive mode): $\mathrm{m} / \mathrm{z}\left(\mathrm{amu} / \mathrm{e}^{-}\right): 283.352$ $\left(\mathrm{M}^{+}\right)$.

\section{Compound 2a}

$1000 \mathrm{mg}$ (1.14 mmol) of the phosphonate PTM derivative (4[bis(2,3,4,5,6-pentachlorophenylmethyl)methyl]-2,3,4,6-tetrachlorobenzyl 
phosphonate) were dissolved in $40 \mathrm{~mL}$ of anhydrous THF under strict inert conditions. The solution was cooled down to $-78^{\circ} \mathrm{C}$ by means of an acetone $/ \mathrm{CO}_{2}(\mathrm{~s})$ bath. Next, $384 \mathrm{mg}(3.42 \mathrm{mmol})$ of potassium tertbutoxide were added and stirred for 20 minutes to form the yellow ylide under an inert argon atmosphere. After that, $141 \mathrm{mg}(1.25 \mathrm{mmol})$ of formyl-TTF were added and the reaction was kept at a low temperature under argon for 3 days. Then, the solution was slowly warmed up to room temperature and acidified with $1.7 \mathrm{~mL}$ of a $2 \mathrm{M}$ solution of $\mathrm{HCl}$ and the product was extracted with 3 portions of $40 \mathrm{ml}$ of $\mathrm{CH}_{2} \mathrm{Cl}_{2}$. The organic phase was washed with water, dried with anhydrous magnesium sulfate and the solvent was evaporated under reduced pressure. Finally, the product was purified by flash column chromatography of silica gel using a mixture of hexane/diethyl ether (50:50) as eluent. $778 \mathrm{mg}(80 \%)$ of product 2a were obtained. Characterization: ${ }^{1} \mathrm{H}-\mathrm{NMR}\left(250 \mathrm{MHz}, \mathrm{C}_{6} \mathrm{D}_{6}\right.$, $\delta(\mathrm{ppm})): 7.21$ (s, 1H; PTM-H), 6.29 (d, $1 \mathrm{H}, \mathrm{J}=16.0 \mathrm{~Hz}) ; 6.13(\mathrm{~d}, 1 \mathrm{H}, \mathrm{J}=$ $16.2 \mathrm{~Hz}) ; 5.52(\mathrm{~s}, 1 \mathrm{H}) ; 5.39(\mathrm{~s}, 2 \mathrm{H})$. FT-IR $\left(\mathrm{KBr}, v\left(\mathrm{~cm}^{-1}\right)\right): 2925(\mathrm{~s}), 2850$ (s), (C-H TTF); 1610 (s) (vinylene bridge); 1530 (m), $1513(\mathrm{~m})(\mathrm{C}=\mathrm{C}$ TTF); 1463 (m); 1356 (s); 1336 (s); 1296 (s); 1134 (m); 1120 (m); 943 (m); 794(s), 779 (s) (C-Cl); 752 (m). UV-VIS-NIR $\left(\mathrm{CH}_{2} \mathrm{Cl}_{2}, \lambda_{\max }\right.$ in $\mathrm{nm}$, $10^{-3} \times \varepsilon$ in $\left.\mathrm{M}^{-1} \cdot \mathrm{cm}^{-1}\right): 290(\mathrm{sh}) ; 322$ (28.4); 456 (5.4). LDI-TOF (negative mode): $\mathrm{m} / \mathrm{z}\left(\mathrm{amu} / \mathrm{e}^{-}\right): 953.705\left(\mathrm{M}^{-{ }^{-1}}\right)$. Cyclic voltammetry $\left(\mathrm{Bu}_{4} \mathrm{NPF}_{6} 0.15 \mathrm{M}\right.$ in $\mathrm{CH}_{2} \mathrm{Cl}_{2}$ as electrolyte): $\mathrm{E}_{1 / 2}^{1}=0.448 \mathrm{~V}$ and $\mathrm{E}_{1 / 2}^{2}=0,965 \mathrm{~V} \mathrm{vs}$. Ag/AgCl.

\section{Compound 2b}

$454 \mathrm{mg}(0.52 \mathrm{mmol})$ of the phosphonated PTM derivative were dissolved in $40 \mathrm{~mL}$ of anhydrous THF under inert conditions. The solution was cooled down to $-78{ }^{\circ} \mathrm{C}$ and $116 \mathrm{mg}(1.03 \mathrm{mmol})$ of potassium tertbutoxide were added and stirred for 20 minutes to form the yellow-orange ylide. After 20 minutes, $147 \mathrm{mg}(0.57 \mathrm{mmol})$ of the aldehyde $\mathbf{3 b}$ were added and the reaction was warmed up to room temperature and stirred for 2 days. Then the mixture was extracted with $\mathrm{CH}_{2} \mathrm{Cl}_{2}$, washed with water, dried with anhydrous $\mathrm{MgSO}_{4}$ and solvents were evaporated under reduced pressure. Finally, the product was purified by column chromatography of silica gel using a mixture of ether and hexane (1:1) to obtain to obtain $362 \mathrm{mg}(71 \%)$ of $\mathbf{2 b}$ as a dark reddish powder. Characterization: ${ }^{1} \mathrm{H}-\mathrm{NMR}\left(250 \mathrm{MHz}, \mathrm{C}_{6} \mathrm{D}_{6}, \delta(\mathrm{ppm})\right): 7.23(\mathrm{~s}, 1 \mathrm{H}) ; 6.49$ (dd, $1 \mathrm{H}, J=15.7,10.5 \mathrm{~Hz}) ; 6,30(\mathrm{~d}, 1 \mathrm{H}, \mathrm{J}=15.7 \mathrm{~Hz}) ; 6.09$ (dd, $1 \mathrm{H}, \mathrm{J}=$ $15.2,10.0 \mathrm{~Hz}) ; 5.87(\mathrm{~d}, 1 \mathrm{H}, \mathrm{J}=15.1 \mathrm{~Hz}) ; 5.50(\mathrm{~s}, 1 \mathrm{H}) ; 5.41(\mathrm{~s}, 2 \mathrm{H})$. FT-IR $\left(v\left(\mathrm{~cm}^{-1}\right)\right): 2951(\mathrm{w}) ; 2922(\mathrm{~m}) ; 2851(\mathrm{~m}) ; 1727(\mathrm{w}) ; 1597(\mathrm{~m}, \mathrm{CH}=\mathrm{CH})$; $1526(\mathrm{~m}) ; 1513(\mathrm{~m}) ; 1458$ (w); 1369 (w); $1337(\mathrm{~m}) ; 1294$ (s); 1239 (w); 1190 (w); $1136(\mathrm{~m}) ; 979(\mathrm{~s}) ; 922(\mathrm{w}) ; 859(\mathrm{w}) ; 828(\mathrm{w}) ; 806(\mathrm{~s}) ; 793(\mathrm{~s})$; $778(\mathrm{~m}) ; 746(\mathrm{w}) ; 734(\mathrm{w}) ; 685(\mathrm{~m})$. UV-VIS-NIR $\left(\mathrm{CH}_{2} \mathrm{Cl}_{2}, \lambda_{\max }\right.$ in $\mathrm{nm}, 10^{-3}$ $\times \varepsilon$ in $\mathrm{M}^{-1} \cdot \mathrm{cm}^{-1}$ ): 289 (sh); 332 (26.4); 463 (5.4). LDI-TOF (positive mode): $\mathrm{m} / \mathrm{z}$ (amu/e): $981.705\left(\mathrm{M}^{+}\right)$. Cyclic voltammetry $\left(\mathrm{Bu}_{4} \mathrm{NPF}_{6} 0.15 \mathrm{M}\right.$ in $\mathrm{CH}_{2} \mathrm{Cl}_{2}$ as electrolyte): $\mathrm{E}_{1 / 2}^{1}=0.447 \mathrm{~V} ; \mathrm{E}_{1 / 2}^{2}=0.958 \mathrm{~V}$.

\section{Compound 2c}

$230 \mathrm{mg}(0.26 \mathrm{mmol})$ of the phosphonated PTM derivative were dissolved in $30 \mathrm{~mL}$ of anhydrous THF under inert conditions. The solution was cooled down to $-78^{\circ} \mathrm{C}$ and $60 \mathrm{mg}(0.52 \mathrm{mmol})$ of potassium tert-butoxide were added and stirred for 20 minutes to form the yellow-orange ylide. After 20 minutes, $85 \mathrm{mg}(0.30 \mathrm{mmol})$ of the aldehyde $3 \mathrm{c}$ were added and the reaction was warmed up to room temperature and stirred for 2 days. Then the mixture was extracted with $\mathrm{CH}_{2} \mathrm{Cl}_{2}$, washed with water, dried with anhydrous $\mathrm{MgSO}_{4}$ and solvents were evaporated under reduced pressure. Finally, the product was purified by column chromatography of silica gel using a mixture of ether and hexane (1:1) to obtain to obtain $105 \mathrm{mg}(40 \%)$ of $2 \mathrm{c}$ as a dark reddish powder. Characterization: ${ }^{1} \mathrm{H}-$ NMR (250 MHz, $\mathrm{C}_{6} \mathrm{D}_{6}, \delta(\mathrm{ppm})$ ): 7.23 (s $\left.1 \mathrm{H}\right) ; 6.64$ (dd, $1 \mathrm{H}, \mathrm{J}=15.6,9.6$ $\mathrm{Hz},) ; 6.36(\mathrm{~d}, 1 \mathrm{H}, \mathrm{J}=15.5 \mathrm{~Hz}) ; 6.1-5.8(\mathrm{~m}, 4 \mathrm{H}) ; 5.51(\mathrm{~s}, 1 \mathrm{H}) ; 5.42(\mathrm{SM}$ 2H). FT-IR $\left(v\left(\mathrm{~cm}^{-1}\right)\right)$ : $2955(\mathrm{w}) ; 2922(\mathrm{w}) ; 2855(\mathrm{w}) ; 1575(\mathrm{~m}, \mathrm{CH}=\mathrm{CH})$; $1525(\mathrm{~m}) ; 1510(\mathrm{~m}) ; 1459(\mathrm{~m}) ; 1370(\mathrm{w}) ; 1337(\mathrm{~m}) ; 1294(\mathrm{~s}) ; 1237(\mathrm{w})$;
1138 (m); 992 (s); 951 (w); 859 (w); 808 (s); 778 (m); 735 (w); $716(w)$ $682(\mathrm{~m})$. LDI-TOF (negative mode): $\mathrm{m} / \mathrm{z}$ (amu/e): $1004.488\left(\mathrm{M}^{-*}\right)$ (positive mode): $\mathrm{m} / \mathrm{z}$ (amu/e): 1003.931 (M"). UV-VIS-NIR $\left(\mathrm{CH}_{2} \mathrm{Cl}_{2}, \lambda_{\max }\right.$ in $\mathrm{nm}, 10^{-3} \times \varepsilon$ in $\left.\mathrm{M}^{-1} \cdot \mathrm{cm}^{-1}\right): 278(\mathrm{sh}) ; 355$ (24.8); 471 (6.4). Cyclic voltammetry ( $\mathrm{Bu}_{4} \mathrm{NPF}_{6} 0.15 \mathrm{M}$ in $\mathrm{CH}_{2} \mathrm{Cl}_{2}$ as electrolyte): $\mathrm{E}_{1 / 2}^{1}=0.462 \mathrm{~V}$; $\mathrm{E}_{1 / 2}^{2}=0.970 \mathrm{~V}$.

\section{Compound 1a}

$100 \mathrm{mg}(0.1 \mathrm{mmol})$ of $\mathbf{2 a}$ were dissolved in $30 \mathrm{~mL}$ of anhydrous THF. 150 $\mu \mathrm{L}(0.15 \mathrm{mmol})$ of tetrabutylammonium hydroxide $1.0 \mathrm{M}$ in methanol were added and the purple solution was stirred for 1 hour. Then, $32 \mathrm{mg}(0.18$ $\mathrm{mmol}$ ) of silver nitrate dissolved in $5 \mathrm{~mL}$ of acetonitrile were added to the solution and stirred for 5 minutes. The solution changes from purple to dark brown with silver $\left(\mathrm{Ag}^{0}\right)$ precipitated. Then, the solution was filtered through silica and the solvent was evaporated under reduced pressure. Finally, the product was precipitated with $\mathrm{MeOH}$ to produce $73 \mathrm{mg}$ of dyad 1a (73\%) as brownish powder. Characterization: FT-IR (KBr, $v$ $\left(\mathrm{cm}^{-1}\right)$ ): 2915 (w), 2889 (w), 1603 (w) (vinylene bridge); $1502(\mathrm{w}), 1474$ (w) (C=C TTF); $1375(\mathrm{~m}) ; 1351(\mathrm{~m}) ; 1334(\mathrm{~s}) ; 1284(\mathrm{~m}) ; 1260(\mathrm{~m}) ; 1250$ (m); 1163 (m); 1134 (m); 1102 (s); 940 (s); 798(w), 780 (w) (C-Cl). UVVIS-NIR $\left(\mathrm{CH}_{2} \mathrm{Cl}_{2}, \lambda_{\max }\right.$ in $\mathrm{nm}, 10^{-3} \times \varepsilon$ in $\left.\mathrm{M}^{-1} \cdot \mathrm{cm}^{-1}\right)$ : 295 (20.6); 323 (sh); 385 (26); 426 (15); 518 (4.3); 957 (0.6). LDI/TOF (positive mode): $\mathrm{m} / \mathrm{z}$ (amu/e): $952\left[\mathrm{M}^{+}\right], 882[\mathrm{M}-2 \mathrm{Cl}]^{+}$. Elemental Analysis: Anal. Calcd. for $\mathrm{C}_{27} \mathrm{H}_{5} \mathrm{Cl}_{14} \mathrm{~S}_{4}\left(\mathrm{C}_{6} \mathrm{H}_{14}\right): \mathrm{C}, 38.11 ; \mathrm{H}, 1.84 ; \mathrm{S}, 12.33$. Found: C, 38.88; $\mathrm{H}, 1,7$; $\mathrm{S}, 12.20$. $\mathrm{CV}\left(\mathrm{Bu}_{4} \mathrm{NPF}_{6} 0.15 \mathrm{M}\right.$ in $\mathrm{CH}_{2} \mathrm{Cl}_{2}$ as electrolyte): $\mathrm{E}_{1 / 2}^{1}=-0.16 \mathrm{~V}$ $\mathrm{E}_{1 / 2}^{2}=0.50 ; \mathrm{E}_{1 / 2}^{3}=1.01 \mathrm{~V}$ vs. Ag/AgCl. ESR $\left(\mathrm{CH}_{2} \mathrm{Cl}_{2} /\right.$ toluene, $\left.220 \mathrm{~K}\right): g=$ $2.0025, a_{1}(H)=1.10 \mathrm{G}$

\section{Compound 1b}

$80 \mathrm{mg}(0.08 \mathrm{mmol})$ of $\mathbf{2 b}$ were dissolved in $20 \mathrm{~mL}$ of anhydrous THF. 120 $\mu \mathrm{L}(0.12 \mathrm{mmol})$ of tetrabutylammonium hydroxide $1.0 \mathrm{M}$ in methanol were added and the purple solution was stirred for 1 hour. Then, $25 \mathrm{mg}(0.14$ $\mathrm{mmol}$ ) of silver nitrate dissolved in $5 \mathrm{~mL}$ of acetonitrile were added to the solution and stirred for 5 minutes. The solution changes from purple to dark brown with silver $\left(\mathrm{Ag}^{0}\right)$ precipitated. Then, the solution was filtered through silica and the solvent was evaporated under reduced pressure. Finally, the product was precipitated with $\mathrm{MeOH}$ to produce $60 \mathrm{mg}$ of dyad 1b $(73 \%)$ as brownish powder. Characterization: FT-IR $(\mathrm{KBr}$, v $\left.\left(\mathrm{cm}^{-1}\right)\right): 2955(\mathrm{~m}) ; 2922(\mathrm{~m}) ; 2851(\mathrm{~m}) ; 1594(\mathrm{w}, \mathrm{CH}=\mathrm{CH}) ; 1525$ (w); 1508 (m); 1458 (w); 1376 (w); 1333 (s); $1259(\mathrm{~m}) ; 1163$ (w); $1136(\mathrm{~m}) ; 1117$ (m); 1066 (m); 971 (s); 923 (w); 865 (w); 815 (s); 795 (s); 778 (s); 735 (s); $708(\mathrm{~m})$. UV-VIS-NIR $\left(\mathrm{CH}_{2} \mathrm{Cl}_{2}, \lambda_{\max }\right.$ in $\mathrm{nm}, 10^{-3} \times \varepsilon$ in $\left.\mathrm{M}^{-1} \cdot \mathrm{cm}^{-1}\right): 273(\mathrm{sh})$; 326 (21.8); 385 (29.3); 456 (12.3); 568 (4.5); 942 (0.6). LDI/TOF (positive mode): $\mathrm{m} / \mathrm{z}\left(\mathrm{amu} / \mathrm{e}^{-}\right): 979.711\left(\mathrm{M}^{+}\right)$. Elemental Analysis: Anal. Calcd. for $\mathrm{C}_{29} \mathrm{H}_{7} \mathrm{Cl}_{14} \mathrm{~S}_{4}\left(\mathrm{C}_{6} \mathrm{H}_{14}\right): \mathrm{C}, 39.43 ; \mathrm{H}, 2.06 ; \mathrm{S}, 12.03$. Found: $\mathrm{C}, 38.8 ; \mathrm{H}, 2.00$; $\mathrm{S}$, 11.67. CV ( $\mathrm{Bu}_{4} \mathrm{NPF}_{6} 0.15 \mathrm{M}$ in $\mathrm{CH}_{2} \mathrm{Cl}_{2}$ as electrolyte): $\mathrm{E}_{1 / 2}^{1}=-0.20 \mathrm{~V}$ $\mathrm{E}_{1 / 2}^{2}=0.44 ; \mathrm{E}_{1 / 2}{ }^{3}=0.96 \mathrm{~V}$ vs. Ag/AgCl. ESR $\left(\mathrm{CH}_{2} \mathrm{Cl}_{2}\right.$ /toluene, $\left.220 \mathrm{~K}\right): g=$ 2.0026, $a_{1}(H)=1.07 \mathrm{G}$

\section{Compound 1c}

$70 \mathrm{mg}(0.07 \mathrm{mmol})$ of $2 \mathrm{c}$ were dissolved in $20 \mathrm{~mL}$ of anhydrous THF. 100 $\mu \mathrm{L}(0.10 \mathrm{mmol})$ of tetrabutylammonium hydroxide $1.0 \mathrm{M}$ in methanol were added and the purple solution was stirred for 1 hour. Then, $21 \mathrm{mg}(0.12$ $\mathrm{mmol}$ ) of silver nitrate dissolved in $5 \mathrm{~mL}$ of acetonitrile were added to the solution and stirred for 5 minutes. The solution changes from purple to dark brown with silver $\left(\mathrm{Ag}^{0}\right)$ precipitated. Then, the solution was filtered through silica and the solvent was evaporated under reduced pressure Finally, the product was precipitated with $\mathrm{MeOH}$ to produce $55 \mathrm{mg}$ of dyad 1c $(78 \%)$ as brownish powder. Characterization: FT-IR $(\mathrm{KBr}$, v $\left(\mathrm{cm}^{-1}\right)$ ): 2953 (w); 2922 (w); 2850 (w); 1571 (m, CH=CH); 1508 (m); 1459 
(m); 1377 (w); 1333 (s); 1318 (s); 1257 (s); 1157 (w); 1137 (m); $116(\mathrm{w})$; 989 (s); 941 (m); 913 (w); 816 (s); 808 (s); 795 (m); 779 (w); 735 (m); 708 (m). UV-VIS-NIR $\left(\mathrm{CH}_{2} \mathrm{Cl}_{2}, \lambda_{\max }\right.$ in $\mathrm{nm}, 10^{-3} \times \varepsilon$ in $\left.\mathrm{M}^{-1} \cdot \mathrm{cm}^{-1}\right): 340$ (24.9); 385 (30.1); 475 (15.9); 607 (7.4); 918 (0.7). LDI/TOF (positive mode): (negative mode): $\mathrm{m} / \mathrm{z}$ (amu/e): $1004.734\left(\mathrm{M}^{-*}\right)$; (positive mode): $\mathrm{m} / \mathrm{z}$ (amu/e): $1003.203\left(\mathrm{M}^{--}\right)$. Elemental Analysis: Anal. Calcd. for $\mathrm{C}_{31} \mathrm{H}_{9} \mathrm{Cl}_{14} \mathrm{~S}_{4}\left(\mathrm{C}_{6} \mathrm{H}_{14}\right): \mathrm{C}, 40.69 ; \mathrm{H}, 2.12 ; \mathrm{S}, 11.74$. Found: $\mathrm{C}, 40.9 ; \mathrm{H}, 2.5$; $\mathrm{S}, 11.83$. $\mathrm{CV}\left(\mathrm{Bu}_{4} \mathrm{NPF}_{6} 0.15 \mathrm{M}\right.$ in $\mathrm{CH}_{2} \mathrm{Cl}_{2}$ as electrolyte): $\mathrm{E}_{1 / 2}^{1}=-0.22 \mathrm{~V}$; $\mathrm{E}_{1 / 2}^{2}=0.40 ; \mathrm{E}_{1 / 2}^{3}=0.92 \mathrm{~V}$ vs. Ag/AgCl. ESR $\left(\mathrm{CH}_{2} \mathrm{Cl}_{2} /\right.$ toluene, $\left.220 \mathrm{~K}\right): g=$ 2.0028, $a_{1}(H)=1.04 \mathrm{G}$

\section{Theoretical Calculations}

Theoretical calculations for the open-shell $\mathbf{1 a - 1 c}$ and closed-shell $\mathbf{2 a - 2 c}$ push-pull systems were performed under the density functional theory (DFT) framework using the Gaussian 09 (version D01) suite of programs. ${ }^{[39]}$ The well-established hybrid exchange-correlation B3LYP functional ${ }^{[40]}$ was used in combination with the standard split-valence Pople's $6-31 G^{\star *}$ basis set $^{[41]}$ and the polarizable continuum solvent model (PCM) to optimize the structure of the molecules. ${ }^{[42]}$ Radical 1a-1c compounds were computed as doublets using the spin-unrestricted UB3LYP/6-31G**+PCM protocol. Time-dependent DFT (TDDFT) calculations $^{[43-45]}$ were carried out for the push-pull systems at the B3LYP/6-31G** and CAM-B3LYP/6-31G** levels in dichloromethane. ${ }^{\text {[46] }}$ The 60 lowest-lying singlet excited states were computed. Atomic charges were calculated by performing a Natural Bond Orbital (NBO) analysis $^{[47]}$ at the B3LYP/6-31G** level in dichloromethane. Spin densities were calculated for the neutral and charged species of the open-shell push-pull structures by using the self-consistent-field density computed at the CAM-B3LYP/6-31G** level of theory in solvent. Cation species of non-radical compounds $\mathbf{2 a - 2 c}$ were computed as doublets, and dication species both as closed-shell singlets and triplets. For the radical compounds $\mathbf{1 a - 1 c}$, both single-charged anions and cations were calculated as closed-shell singlets and triplets, and dications as doublets. Hyperpolarizabilities $(\beta)$ were calculated at the BH\&HLYP/6-31G** [40] and B3LYP/6-31G** levels in PCM-dichloromethane according to the procedure detailed in the Supporting Information.

\section{Acknowledgements}

This work was supported by the EU Training Network (ITN) "iSwitch" (GA No. 642196), the Spanish Ministry of Economy and Competitiveness MINECO (projects CTQ2013-40480-R and CTQ2015-71154-P), the Networking Research Center on Bioengineering, Biomaterials, and Nano- medicine (CIBERBBN), the Generalitat de Catalunya (grant 2014-SGR-17), the Generalitat Valenciana (PROMETEO/2016/135) and European Feder funds (CTQ2015-71154-P). ICMAB acknowledges support from the MINECO through the "Severo Ochoa" Programme for Centres of Excellence in R\&D (SEV-2015-0496). ICMol thanks the MINECO for the Unidad de Excelencia María de Maeztu MDM-2015-0538. M.S. and J.C. are grateful to MECD of Spain for FPU predoctoral grants. We thank Amable Bernabé for MALDI spectroscopy and Vega Lloveras for ESR spectroscopy.

Keywords: Donor-Acceptor $•$ NLO properties • tetrathiafulvalene - PTM radical • intramolecular charge-transfer
Organic Molecules and Crystals, Academic Press, Inc., Orlando, 1987.

[2] J. Zyss, Molecular Nonlinear Optics, Academic Press, Inc., New York, 1993.

[3] N. O. Prassad, D. J. Williams, Introduction to Nonlinear Optical Effects in Molecules and Polymers, WileyInterscience, 1991.

[4] D. Burland, Chem. Rev. 1994, 94, 1-2.

[5] S. R. Marder, B. Kippelen, A. K.-Y. Jen, N. Peyghambarian, Nature 1997, 388, 845-851.

[6] D. R. Kanis, M. A. Ratner, T. J. Marks, Chem. Rev. 1994 94, 195-242.

[7] N. J. Long, Angew. Chemie - Int. Ed. 1995, 34, 21-38

[8] I. Asselberghs, K. Clays, A. Persoons, M. D. Ward, J. McCleverty, J. Mater. Chem. 2004, 14, 2831-2839.

[9] A. I. De Lucas, N. Martín, L. Sánchez, C. Seoane, R. Andreu, J. Garín, J. Orduna, R. Alcalá, B. Villacampa, Tetrahedron 1998, 54, 4655-4662.

[10] M. R. Bryce, A. Green, A. J. Moore, D. F. Perepichka, A. S. Batsanov, J. a K. Howard, I. Ledoux-rak, M. Gonza, L. Segura, J. Garín, J. Orduna, R. Alcalá, B. Villacampa, Eur. J. Org. Chem. 2001, 1927-1935.

[11] M. González, L. Segura, C. Seoane, N. Martín, J. Garín, J. Orduna, R. Alcala, B. Villacampa, V. Hernández, J. T. López Navarrete, J. Org. Chem. 2001, 66, 8872-8882.

[12] J. L. Segura, N. Martín, Angew. Chemie - Int. Ed. 2001, 40 1372-1409.

[13] S. Alías, R. Andreu, S. Franco, J. Garín, A. Gragera, J. Orduna, P. Romero, B. Villacampa, M. Allain, J. Org. Chem. 2007, 72, 6440-6446.

[14] S. Alías, R. Andreu, M. J. Blesa, M. A. Cerdán, S. Franco, J. Garín, C. López, J. Orduna, J. Sanz, R. Alicante, B. Villacampa, M. Allain, J. Org. Chem. 2008, 73, 5890-5898.

[15] C. G. Liu, W. Guan, P. Song, L. K. Yan, Z. M. Su, Inorg Chem. 2009, 48, 6548-6554.

[16] C. G. Liu, X.-H. Guan, Phys. Chem. Chem. Phys. 2012, 14, 5297-5306.

[17] Y. Si, G. Yang, Z. Su, J. Mater. Chem. C 2013, 1, 13991406.

[18] M. Bendikov, F. Wudl, D. F. Perepichka, Chem. Rev. 2004, 104, 4891-4945.

[19] J.-F. Nicoud, C. Serbutoviez, G. Puccetti, I. Ledoux, J. Zyss, Chem. Phys. Lett. 1990, 175, 257-261.

[20] L. Angeloni, A. Caneschi, L. David, A. Fabretti, F. Ferraro, R. Sessolib, J. Mater. Chem. 1994, 4, 1047-1053. 
[21] S. Di Bella, I. Fragala, I. Ledoux, T. J. Marks, J. Am. Chem. Soc. 1995, 117, 9481-9485.

[22] S. Di Bella, I. Fragalà, T. J. Marks, M. a. Ratner, J. Am. Chem. Soc. 1996, 118, 12747-12751.

[23] K. Yoneda, M. Nakano, K. Fukuda, H. Matsui, S. Takamuku, Y. Hirosaki, T. Kubo, K. Kamada, B. Champagne, Chem. Eur. J. 2014, 11129-11136.

[24] Z. Zeng, S. Lee, M. Son, K. Fukuda, P. M. Burrezo, X. Zhu, Q. Qi, R.-W. Li, J. T. López-Navarrete, J. Ding, J. Casado, M. Nakano, D. Kim, J. Wu, J. Am. Chem. Soc. 2015, 137, $8752-8583$.

[25] I. Ratera, S. Marcen, S. Montant, D. Ruiz Molina, C. Rovira, J. Veciana, J. F. Létard, E. Freysz, Chem. Phys. Lett. 2002, $363,245-251$.

[26] I. Ratera, D. Ruiz-Molina, C. Sporer, S. Marcen, S. Montant, J.-F. Létard, E. Freysz, C. Rovira, J. Veciana, Polyhedron 2003, 22, 1851-1856.

[27] C. Sporer, I. Ratera, D. Ruiz-Molina, Y. Zhao, J. VidalGancedo, K. Wurst, P. Jaitner, K. Clays, A. Persoons, C. Rovira, J. Veciana, Angew. Chemie - Int. Ed. 2004, 43, 5266-5268.

[28] I. Ratera, J. Veciana, Chem. Soc. Rev. 2012, 41, 303.

[29] J. Guasch, L. Grisanti, V. Lloveras, J. Vidal-Gancedo, M. Souto, D. C. Morales, M. Vilaseca, C. Sissa, A. Painelli, I. Ratera, C. Rovira, J. Veciana, Angew. Chemie - Int. Ed. 2012, 51, 11024-11028.

[30] J. Guasch, L. Grisanti, M. Souto, V. Lloveras, J. VidalGancedo, I. Ratera, A. Painelli, C. Rovira, J. Veciana, J. Am. Chem. Soc. 2013, 135, 6958-6967.

[31] M. Souto, J. Guasch, V. Lloveras, P. Mayorga, J. T. López Navarrete, J. Casado, I. Ratera, C. Rovira, A. Painelli, J. Veciana, J. Phys. Chem. Lett. 2013, 4, 2721-2726.

[32] M. Souto, V. Lloveras, S. Vela, M. Fumanal, I. Ratera, J. Veciana, J. Phys. Chem. Lett. 2016, 7, 2334-2339.

[33] M. Souto, M. V. Solano, M. Jensen, D. Bendixen, F. Delchiaro, A. Girlando, A. Painelli, J. O. Jeppesen, C. Rovira, I. Ratera, J. Veciana, Chem. Eur. J. 2015, 21, $8816-8825$.

[34] M. Souto, H. Cui, M. Peña-Álvarez, V. G. Baonza, H. O. Jeschke, M. Tomic, R. Valent, D. Blasi, I. Ratera, C. Rovira, J. Veciana, J. Am. Chem. Soc. 2016, 138, 11517-11525.

[35] M. Souto, C. Rovira, I. Ratera, J. Veciana, CrystEngComm 2017, 19, 197-206.

[36] D. C. Green, J. Org. Chem. 1979, 44, 1476-1479.

[37] R. Andreu, J. Garín, J. Orduna, M. Saviron, J. Cousseau, a. Gorgues, V. Morrison, T. Nozdryn, J. Becher, R. P. Clausen, M. R. Bryce, P. J. Skabara, W. Dehaen, 1994, 35, 92439246.
[38] C. Rovira, D. Ruiz-Molina, O. Elsner, J. Vidal-Gancedo, J. Bonvoisin, J. P. Launay, J. Veciana, Chem. Eur. J. 2001, 7, 240-250.

[39] M. J. Frisch, G. W. Trucks, H. B. Schlegel, G. E. Scuseria, M. A. Robb, J. R. Cheeseman, G. Scalmani, V. Barone, B. Mennucci, G. A. Petersson, H. Nakatsuji, M. Caricato, X. Li, H. P. Hratchian, A. F. Izmaylov, J. Bloino, G. Zheng, J. L. Sonnenberg, M. Hada, M. Ehara, K. Toyota, R. Fukuda, J. Hasegawa, M. Ishida, T. Nakajima, Y. Honda, O. Kitao, H. Nakai, T. Vreven, J. A. Montgomery, J. E. Peralta, F. Ogliaro, M. Bearpark, J. J. Heyd, E. Brothers, K. N. Kudin, V. N. Staroverov, R. Kobayashi, J. Normand, K. Raghavachari, A. Rendell, J. C. Burant, S. S. Iyengar, J. Tomasi, M. Cossi, N. Rega, J. M. Millam, M. Klene, J. E. Knox, J. B. Cross, V. Bakken, C. Adamo, J. Jaramillo, R. Gomperts, R. E. Stratmann, O. Yazyev, A. J. Austin, R. Cammi, C. Pomelli, J. W. Ochterski, R. L. Martin, K. Morokuma, V. G. Zakrzewski, G. A. Voth, P. Salvador, J. J. Dannenberg, S. Dapprich, A. D. Daniels, Farkas, J. B. Foresman, J. V. Ortiz, J. Cioslowski and D. J. Fox, Gaussian 09, Revision D.01, Wallingford CT, 2009.

[40] A. D. Becke, J. Chem. Phys. 1993, 98, 5648-5652.

[41] V. A. Rassolov, M. A. Ratner, J. A. Pople, P. C. Redfern, L. A. Curtiss, J. Comput. Chem. 2001, 22, 976-984.

[42] J. Tomasi, B. Mennucci, R. Cammi, Chem. Rev. 2005, 105, 2999-3094.

[43] C. Jamorski, M. E. Casida, D. R. Salahub, J. Chem. Phys. 1996, 104, 5134-5147.

[44] M. E. Casida, C. Jamorski, K. C. Casida, D. R. Salahub, J. Chem. Phys. 1998, 108, 4439-4449.

[45] M. Petersilka, U. J. Gossmann, E. K. U. Gross, Phys. Rev. Lett. 1996, 76, 1212-1215.

[46] T. Yanai, D. P. Tew, N. C. Handy, Chem. Phys. Lett. 2004, 393, 51-57.

[47] A. E. Reed, L. A. Curtiss, F. Weinhold, Chem. Rev. 1998, $88,899-926$. 


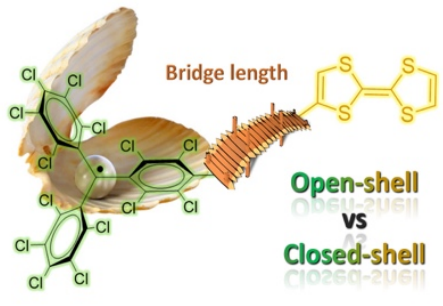

Three conjugated donor- $\pi$-acceptor radical systems based on a tetrathiafulvalene (TTF) unit, as electron-donor, connected to a polychlorotriphenylmethyl (PTM) radical, as electron-acceptor, through different vinylene units as bridge have been synthesized and characterized. The linear and non-linear optical properties of these derivatives have been theoretically calculated by comparing with their non-radical analogues. 